\title{
STUDY OF SPRING WHEAT VARIETIES FOR IDENTIFICATION OF FORMS RESISTANT TO CADMIUM
}

\author{
R.A. Alybayeva*, M.F. Mulyukova, A.E. Bektiyar, V.I. Kruzhayeva, S.D. Atabayeva \\ and S. Sh. Asrandina \\ Kazakh National University named after al-Farabi, Almaty, Republic of Kazakhstan
}

\begin{abstract}
The purpose of our study was the identification of spring wheat varieties resistant to cadmium, a priority pollutant in the East Kazakhstan region. The experiments were carried out in the condition of model environmental pollution on 14-day sprouts of various spring wheat varieties, that were grown on a nutrient mixture, containing $0.1 \mathrm{mM}$ of $\mathrm{CaSO}_{4}$ and $\mathrm{Cd}$ ions at a concentration of 40 $\mathrm{mg} / \mathrm{l}$. Screening of spring wheat varieties under the conditions of the model experiment made it possible to identify resistant and sensitive genotypes. In terms of growth and accumulation of cadmium in the aboveground organs, the most resistant to cadmium spring wheat varieties are Samal and Kaiyr, the least resistant are the varieties Lutescens and Zhenis. In terms of growth and accumulation of cadmium in the roots, the most resistant varieties of spring wheat were Kazakhstan15 and Kazakhstan Early, the most unstable - the variety Lutescens. Chlorophyll $a$ is more sensitive to the action of cadmium ions than chlorophyll 6 . Cadmium-resistant varieties can be used in field studies of soil contamination with cadmium to identify promising forms that combine metal resistance with high yield and resistance to weather conditions.
\end{abstract}

Keywords: cadmium, spring wheat, growth parameters, cadmium content, chlorophyll content, sensitive and resistant genotypes

\section{Background. Objectives and goals}

Pollution of the environment, in particular by chemicals, is one of the most powerful factors of destruction of the biosphere components. At present, a large number of pollutants enter the biosphere. Among them, a significant place is occupied by heavy metals. Heavy metals are the most toxic among chemical elements [1].

One of the ways to obtain clean commercial products on soils contaminated with heavy metals is to create, and use in the production, technogenic resistant varieties of agricultural crops. The development of this method raises the initial task of studying gene pool of the cultivated and wild plants and allocation of donors, accumulating minimum amount of contaminants in the commercial part of the crop [2]. The evaluation of selection material and the direction of researches on the principles of the use of attributes, that allow to accumulate a minimum number of ecotoxicants, will make it possible to reduce terms of selection work $[3,4]$. In connection with the task of studying the gene pool of cultivated plants in conditions of technogenic pollution, the subject of the study was the screening of varieties of spring wheat for metal resistance in order to identify the promising types for cultivation in the East Kazakhstan region, and selection donors that accumulate minimum amount of pollutants.

\section{Methods}

The objects of research are different genotypes of spring wheat from the collection of the Kazakh Research Institute of Agriculture (KIA): Kazakhstan Early, Erythrospermum, Kaiyr, Lutescens, Zhenis, Kazakhstan-25, Samal, Samgau, Almaken, Kazakhstan-15. 
Plant cultivation. The experiments were performed on 14-day sprouts of various wheat varieties grown on a nutrient mixture containing $0.1 \mathrm{mM} \mathrm{CaSO}_{4}$ and cadmium ions at a concentration of $40 \mathrm{mg} / \mathrm{l}$ (as a CdSO $\mathrm{Salt}_{\text {) }}$. Samples were grown in the aquatic environment at $\mathrm{t}-20^{\circ} \mathrm{C}$ during the day and $16^{\circ} \mathrm{C}$ at night, with a 10 -hour photoperiod, light intensity - 5 thousand lux, humidity - 60\%. Growth parameters, tolerance index, cadmium content in roots and aerial organs and the content of chlorophyll $a$ and $b$ in sprouts were determined.

Determination of growth parameters and the tolerance index. Measurement of biometric indicators was carried out by generally accepted methods. The tolerance index or the Wilkins coefficient was calculated by the formula: $I_{t}=I_{m e} / I_{c}$, where $I_{m e}$ is the root increment in the solution with studied metal, and $I_{c}$ is the root increment on the solution without metal [5].

Determination of heavy metals. Cadmium in soil and plant samples were determined by atomic absorption method on the device A Analyst 300 of "Perkin Elmer" firm. Sample preparation was carried out using a heating unit «Hot Block» with the addition of concentrated nitric acid and hydrochloric acid at a temperature of $90 \pm 5^{\circ}$ $\mathrm{C}$, in accordance with standard operating procedures. Weighed portion of sample was placed in disposable sample cups; $5 \mathrm{ml}$ of $50 \%$ nitric acid and $0.5 \mathrm{ml}$ of concentrated hydrochloric acid were added. Samples were mixed well to liquid clay condition, covered with a watch glass and placed in a heating block. The sample was heated to a temperature of $90 \pm 5^{\circ} \mathrm{C}$, and evaporated for 10-15 minutes without boiling. Then the sample was cooled, $5 \mathrm{ml}$ concentrated $\mathrm{HNO}_{3}$ was added and heated again for 30 minutes. Content of capacitances were evaporated without boiling at a temperature of $90 \pm 5^{\circ} \mathrm{C}$ for approximately up to $5 \mathrm{ml}$ during 2 hours, avoiding foaming. After that the sample was cooled and the volume was adjusted to $50 \mathrm{ml}$ with deionized water. To calibrate the device the calibration blank have been used, consisting of deionized water and $1 \% \mathrm{HNO}_{3}$ solution and standard samples of the company «High Purity". After calibration of the devise, readings of analyzed samples were taken. Accuracy of analysis performance was checked by the screening standard of the company «Merck».

The content of heavy metal in the sample was calculated according to the formula:

C device $\mathrm{x}$ V samp. x FD

C mg / kg = -------------------------

M

wherein

C device - devise reading ( $\mathrm{mg} / \mathrm{l})$;

V samp. - final volume of samples (ml);

FD - dilution factor;

M - weighed sample (g).

Determination of chlorophyll content. The content of photosynthetic pigments was determined by direct spectrophotometry method of undiluted acetone extracts according to Holm-Wettstein [6,7,8]. Absorption spectras of the extracts were recorded on a spectrophotometer SPEKS SCP-705. 


\section{Results}

Study of the effect of cadmium on the growth of spring wheat plants. A study of the genotypic specificity of wheat for resistance to heavy metals was carried out for cadmium, a priority pollutant in the East Kazakhstan region. Cadmium is one of the most toxic environmental pollutants for plants. Increased concentrations of cadmium in the root-inhabited environment cause plants to slow growth and development [9]. Our studies of the influence of cadmium on growth parameters of wheat seedlings in laboratory conditions showed that cadmium ions suppress plant growth (Figure 1).

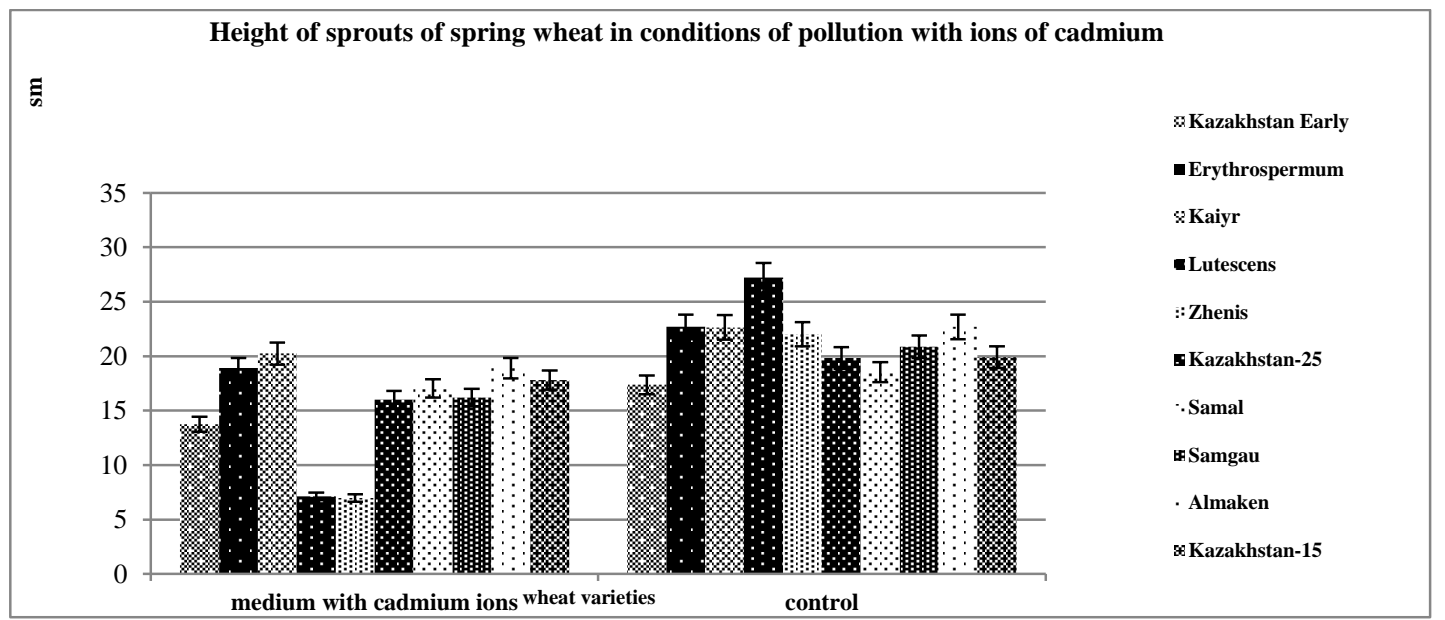

Figure 1. Influence of the presence of cadmium ions in the growth medium on the growth of seedlings of various varieties of spring wheat.

Our study of growth parameters of different wheat varieties have allowed to reveal specific features of cadmium toxicity depending on genotypic differences of wheat plants. In the study of genotypes from the KIA collection, it was shown (Figure 2) that according to the growth of the above-ground organs with a high cadmium concentration in the growing medium, the genotypes can be arranged as follows: Samal > Kaiyr > Kazakhstan$15>$ Erythrospermum $>$ Almaken $>$ Kazakhstan-25 > Kazakhstan Early > Samgau $>$ Zhenis $>$ Lutescens (Figure 2 ). The most resistant to the adverse effect of cadmium ions, according to the growth indices of above-ground organs, were the varieties of spring wheat Samal, Kaiyr and Kazakhstan-15. In these genotypes, the growth inhibition of seedlings is 8.0, 10.6 and 10.7 percent, respectively, compared to the control.

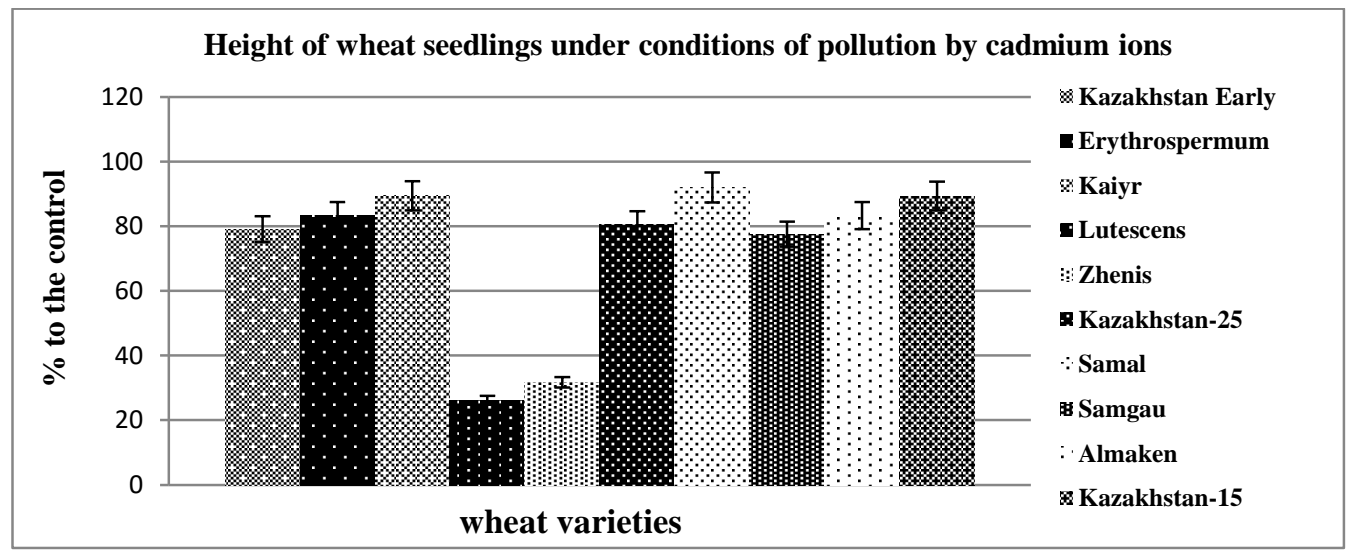

Figure 2. Reduction in the length of sprouts of different varieties of wheat (in percentage to the control) in conditions of environmental contamination with cadmium ions.

The average level of resistance to adverse effects of cadmium ions in spring wheat varieties Erythrospermum, Almaken, Kazakhstan-25, Kazakhstan Early, Samgau. By the growth of seedlings, the most unstable to the 
adverse effects of cadmium ions were spring wheat varieties Zhenis and Lutescens. In these varieties of spring wheat growth suppression seedlings compared to control occurs at 68.3 and 73.8 percent, respectively (figure 3 ).

Our studies of the effect of cadmium on the growth parameters of wheat roots under the conditions of the model experiment have shown that cadmium ions suppress the growth of plant roots. At the same time, the suppression of root growth is more significant than the suppression of growth of seedlings (figures 3 and 1).

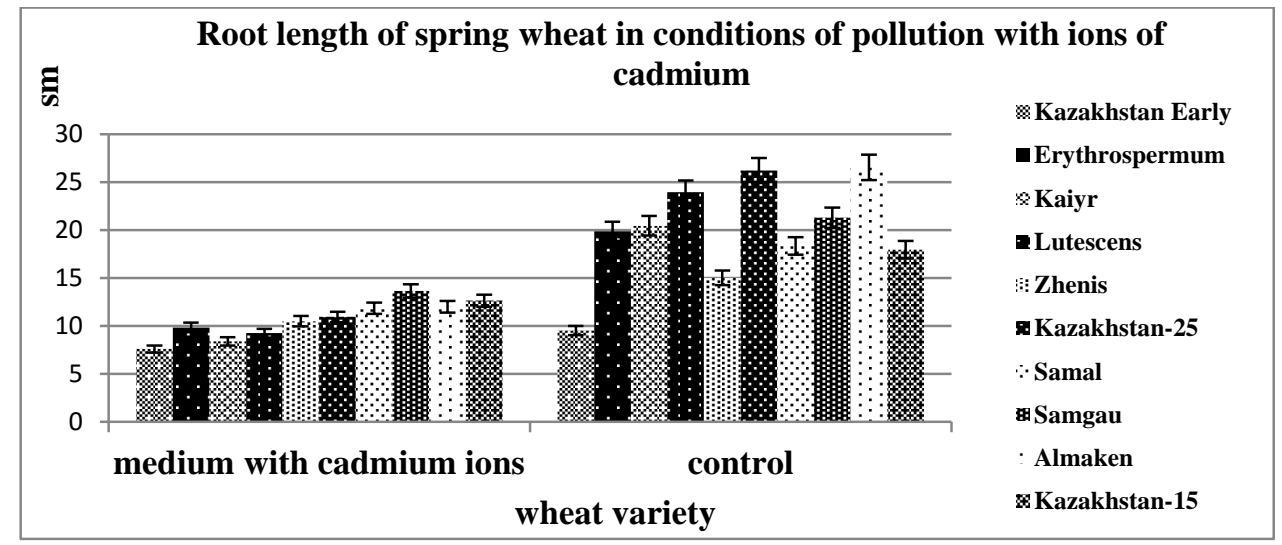

Figure 3. The influence of the presence of cadmium ions in the growing medium on the growth of roots of different wheat varieties.

Upon the root growth, when the salts of cadmium applied to the nutritional environment, genotypes can be arranged as follows: Kazakhstan Early > Kazakhstan-15 > Zhenis > Samal > Samgau > Erythrospermum > Almaken > Kazakhstan-25 > Kaiyr > Lutescens (figure 4).

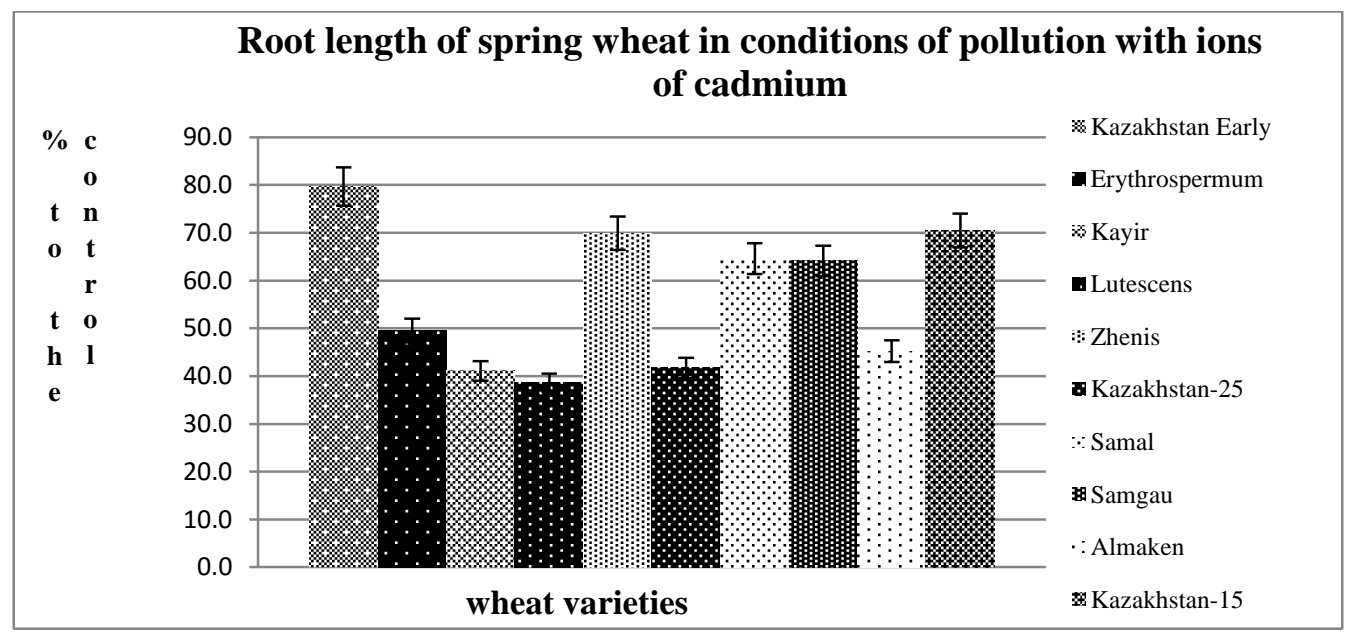

Figure 4. Reducing the length of roots of different wheat varieties (as a percentage of control) in terms of environmental pollution with cadmium ions.

The most resistant to the adverse action of ions of cadmium in the root system were varieties of spring wheat Kazakhstan Early, Kazakhstan-15 and Zhenis. Suppression of root growth compared with the control occurs by 20.3, and 29.5 and 30.1 percent. The average level of resistance of roots to the adverse effects of cadmium were detected in wheat varieties Samal, Samgau, Erythrospermum and Almaken. Less resistance to the adverse effect of cadmium showed varieties of spring wheat Kazakhstan-25 and Kaiyr. Root growth suppression compared to control occurs at 58.2 and 58.9 percent (figure 4).

The most unstable to the adverse effects of cadmium ions were the roots of plants of the variety Lutescens.. Suppression of root growth compared with the control occurs by 61.4 percent (see figure 4 ). 
Wilkins coefficient was also determined, which shows the tolerance of plants to heavy metals (table 1).

Table 1. Wilkins coefficient or index of tolerance of wheat germ roots in conditions of contamination of the growing medium with cadmium ions.

\begin{tabular}{lcccccccccc}
\hline $\begin{array}{l}\text { Genoty } \\
\text { pes of } \\
\text { wheat }\end{array}$ & $\begin{array}{c}\text { Kazakh } \\
\text { stan } \\
\text { Early }\end{array}$ & $\begin{array}{c}\text { Erythro } \\
\text { spermum }\end{array}$ & Kaiyr & $\begin{array}{c}\text { Lutes } \\
\text { cens }\end{array}$ & $\begin{array}{c}\text { Zhe } \\
\text { nis }\end{array}$ & $\begin{array}{c}\text { Kazakh } \\
\text { stan-25 }\end{array}$ & $\begin{array}{c}\text { Sa } \\
\text { mal }\end{array}$ & $\begin{array}{c}\text { Sam } \\
\text { gau }\end{array}$ & $\begin{array}{c}\text { Alma } \\
\text { ken }\end{array}$ & $\begin{array}{c}\text { Kazakh } \\
\text { stan-15 }\end{array}$ \\
\hline Im & 7,60 & 9,85 & 8,40 & 9,25 & $\begin{array}{c}10,5 \\
0\end{array}$ & 10,95 & 11,84 & 13,65 & 12,00 & 12,65 \\
\hline Ic & 9,54 & 19,87 & 20,44 & 23,95 & $\begin{array}{c}15,0 \\
2\end{array}$ & 26,22 & 18,34 & 21,29 & 26,52 & 17,95 \\
\hline It & 0,80 & 0,50 & 0,41 & 0,39 & 0,70 & 0,42 & 0,65 & 0,64 & 0,45 & 0,70 \\
\hline
\end{tabular}

Wilkins coefficient or the index of tolerance, with a high concentration of ions of cadmium in the growing medium, is the greatest in varieties of spring wheat Kazakhstan Early, Kazakhstan-15 and Zhenis, the average in varieties - Samal, Samgau, Erythrospermum and Almaken, smaller - varieties Kazakhstan-25 and Kaiyr, the least - in the variety Lutescens (table 3). According to the results of the study of root growth, when contaminated with cadmium ions, and according to the tolerance index, spring wheat varieties Kazakhstan early, Kazakhstan-15 and Zhenis can be identified as genotypes with the most stable root system to the adverse effects of this element. The most unstable to the adverse effects of cadmium ions, by the results of the determination of both parameters, were roots of plants of the Lutescens variety.

Thus, the varieties of spring wheat Samal, Kaiyr and Kazakhstan-15 were the most resistant to the action of cadmium ions by the growth of the aboveground organs, Zhenis and Lutescens varieties were the most unstable to the adverse action of this metal. By root growth, the most resistant to the action of cadmium ions were varieties Kazakhstan Early, Kazakhstan-15 and Zhenis, the most unstable was the variety of spring wheat Lutescens.

\section{Accumulation and distribution of cadmium in the organs of spring wheat depending on varietal differences of samples in in the conditions of model test}

Not being an essential element for plant life, cadmium is actively absorbed and easily transported through the plant, accumulates in all organs, has a cumulative effect [10]. Cadmium also accumulates in plant seeds. Thus, the content of a microelement in wheat grain is higher than in stems and leaves of plants [11, 12]. According to some researchers, the level of heavy metal cadmium in food is a problem of food security. Reducing cadmium in grain is one of the priorities of breeding programs [12].

Cadmium that enters surface organs may subsequently accumulate in the seeds, so we have focused on the translocation of cadmium in the aerial part of the plants. Varieties with the least content of cadmium in the aerial organs are subsequently used for field studies to identify promising for agricultural production forms, which are characterized by minimal cadmium accumulation in the seeds and in the same time characterized by high productivity and resistance to unfavorable climatic conditions of the environment.

The results of determination of cadmium content in the aerial organs of seedlings of the studied spring wheat varieties showed that at a dose of $40 \mathrm{mg} / \mathrm{l}$ of cadmium in the medium, the smallest amount in the aerial organs accumulate sprouts of spring wheat varieties Samal and Kayyr (figure 5).

The greatest number of cadmium in the aboveground organs, in these conditions of experiment, accumulate seedlings of spring wheat varieties Lutescens and Zhenis. The other genotypes occupy an intermediate position between them. 


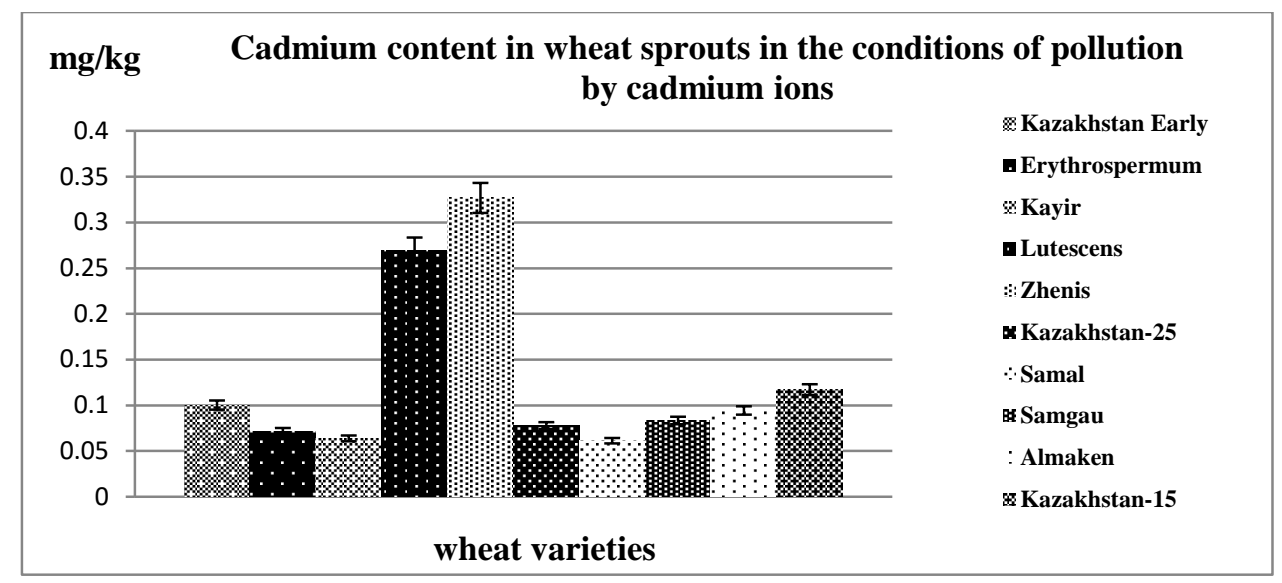

Figure 5. The content of cadmium in aboveground organs of different genotypes of wheat in terms of contamination of the growing environment with cadmium ions.

Investigation of cadmium content in roots of seedlings of various genotypes of spring wheat showed that at the dose of $40 \mathrm{mg} / \mathrm{l}$ in the environment, the smallest amount of it accumulated in the roots, the seedlings of spring wheat varieties Kazakhstan-15, Kazakhstan Early and Zhenis (figure 6).

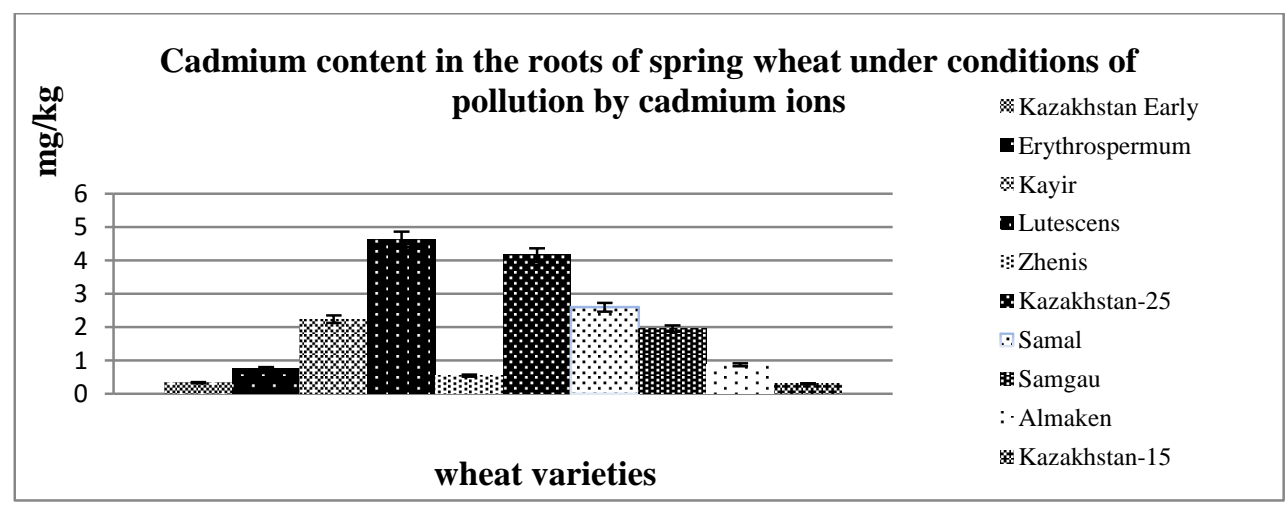

Figure 6. The content of cadmium in roots of various wheat genotypes in terms of contamination of the growing environment with cadmium ions.

Under these conditions, the greatest amount of cadmium accumulated in the roots of plants of the variety Lutescens.. The remaining varieties occupy an intermediate position between them.

According to the study of accumulation of cadmium in the aboveground organs of plants of different spring wheat varieties, varieties Samal and Kair can be selected as the genotypes resistant to translocation of cadmium in the aboveground organs. Accirding to the results of research of cadmium accumulation in aboveground organs of spring wheat it is possible to allocate varieties Kazakhstan-15, Kazakhstan Early and Zhenis as genotypes with the greatest root resistance to action of cadmium. Research of accumulation of cadmium in roots and aboveground organs, of accumulation of dry matter, and also of growth parameters of wheat seedlings of various genotypes allowed to reveal the most sensitive and stable genotypes. The most resistant to cadmium were varieties Samal and Kaiyr, and the most sensitive - spring wheat variety Lutescens.

\section{Effect of cadmium on chlorophyll content in leaves of seedlings of different wheat varieties}

Increased concentrations of cadmium in the root medium cause slowing of growth and development of plants [9], as well as disturbances in the course of basic physiological processes [13]. To understand the causes of negative impact of cadmium, it is important to know what specific anatomical, morphological, physiological and 
biochemical changes it causes in different parts of the plant, and, above all, in the leave, as the main organ of photosynthesis.

The study of the effect of cadmium on the photosynthetic apparatus of wheat plants showed the presence of certain changes in the number of basic forms of pigments. A slight increase in chlorophyll $a$ was found in the presence of cadmium in most varieties (figure 7). The same data were obtained from other authors [14].

Earlier it was repeatedly noted that the photosynthetic apparatus of plants is one of the first to react to stress [15] and the state of the pigment system determines the efficiency of photoassimilation of $\mathrm{CO}_{2}[16]$.

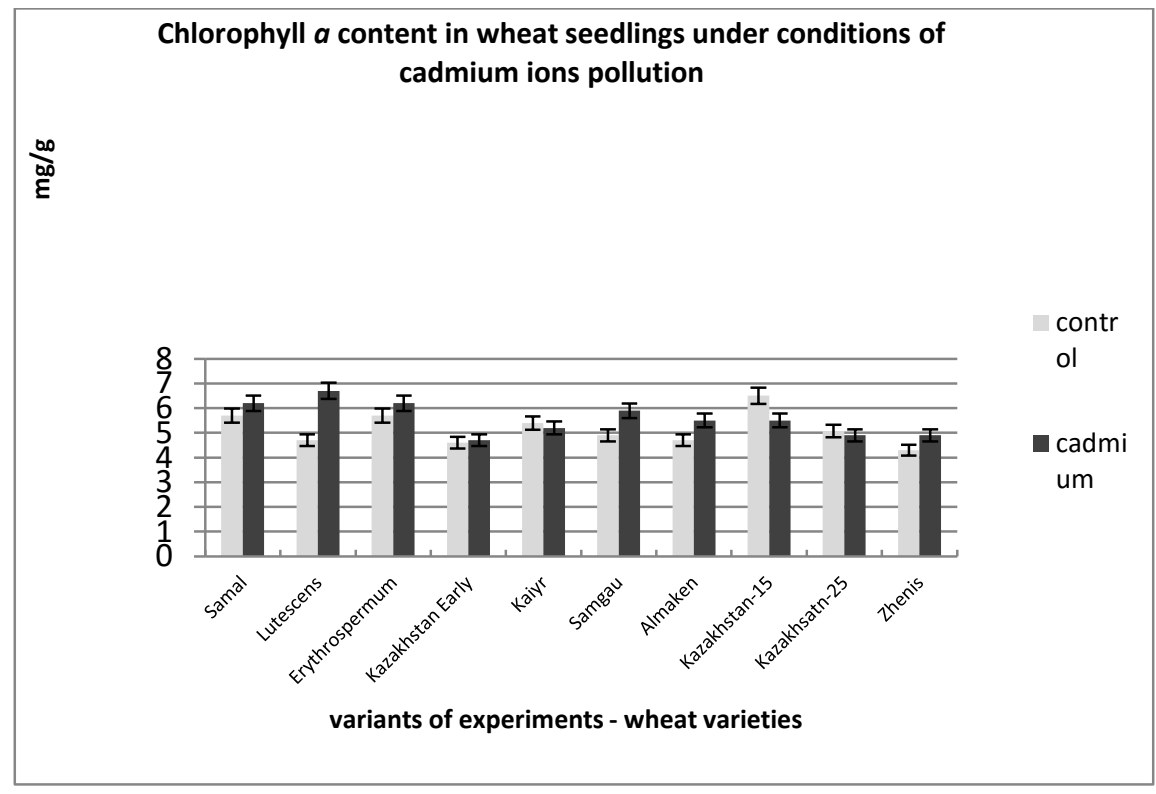

Figure 7. Effect of cadmium on chlorophyll a content in wheat leaves.

Our studies have shown that the content of chlorophyll $b$ in seedlings of different varieties of wheat is different. In a medium with the addition of cadmium ions, the chlorophyll $b$ content in the seedlings of different varieties of wheat is also uneven (figure 8).

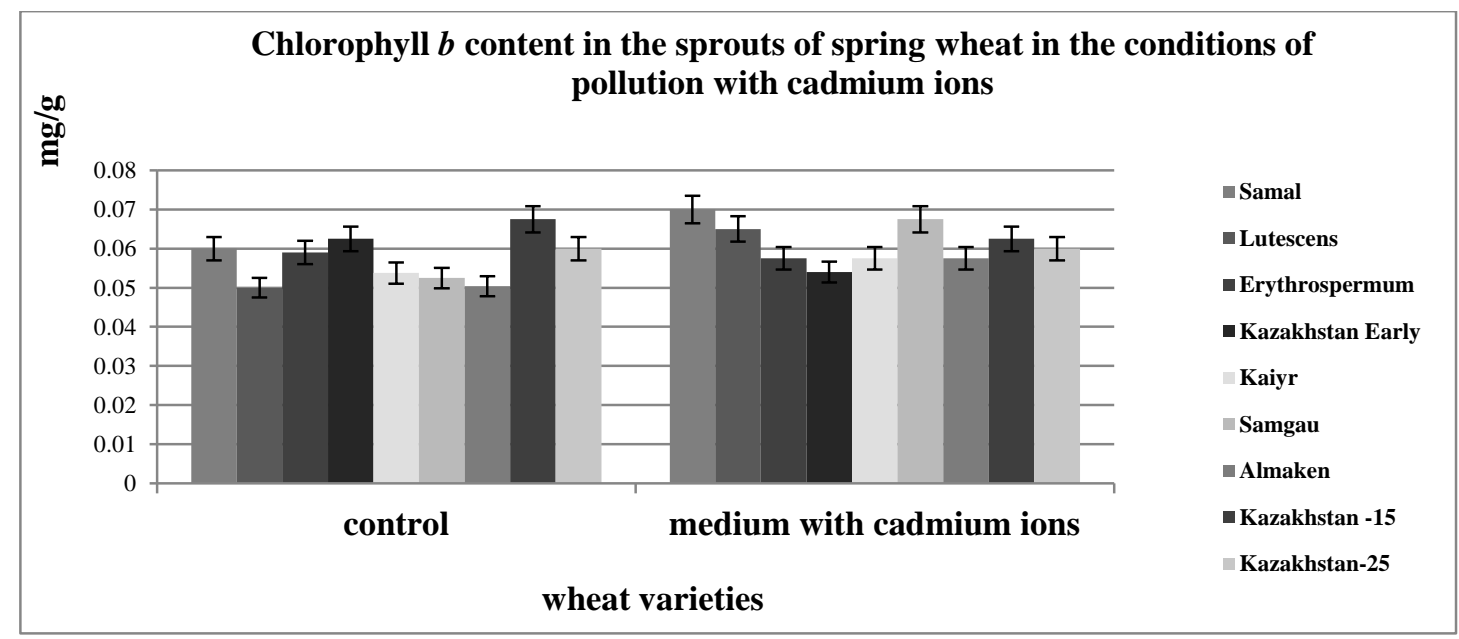

Figure 8. Chlorophyll b content in seedlings of different varieties of wheat in the medium contaminated with cadmium ions.

Erofeev E. A. and Naumova M. M. showed that cadmium sulfate in small concentrations leads to a decrease in the amount of chlorophyll a and b compared to the plant level of the control group. However, in the area of high 
salt concentrations, the amount of chlorophyll in T. Aestivum shoots increased to the level of the control group plants [17]. Also, for example, an increase in the total concentration of photosynthetic pigments is revealed in the leaves of clover, as a response to the presence of contaminants. The authors have made an assumption that the high total concentration of pigments of photosynthesis in the studied plants may be associated with the activation of photosynthetic apparatus, provoked by high energy costs, which are associated with the neutralization of the influence of pollutants [18].

At the same time, chlorophyll $a$ content varied more strongly than chlorophyll $\mathrm{b}$.

The ratio of chlorophyll $a / b$ and the ratio of chlorophyll $(a+b)$ to carotenoids can be significant indicators of the stability of the pigment complex to heavy metals [15].

These values are normally stable, but can change quickly under the influence of stress factors. Changes in the ratio of the content of photosynthetic pigments affect the activity of the photosynthetic apparatus, affecting the rate of accumulation of assimilates, growth and productivity of plants [15, 19].

Our data suggest that chlorophyll $a$ is more sensitive to cadmium ions than chlorophyll $b$ (figure 9). Similar data were obtained by other authors. Maleva M. G. with co-authors revealed that chlorophyll $a$ is more sensitive to $\mathrm{Cu}$ and the co-action of $\mathrm{Cu}$ and $\mathrm{Mn}$ than chlorophyll $b$ [20].

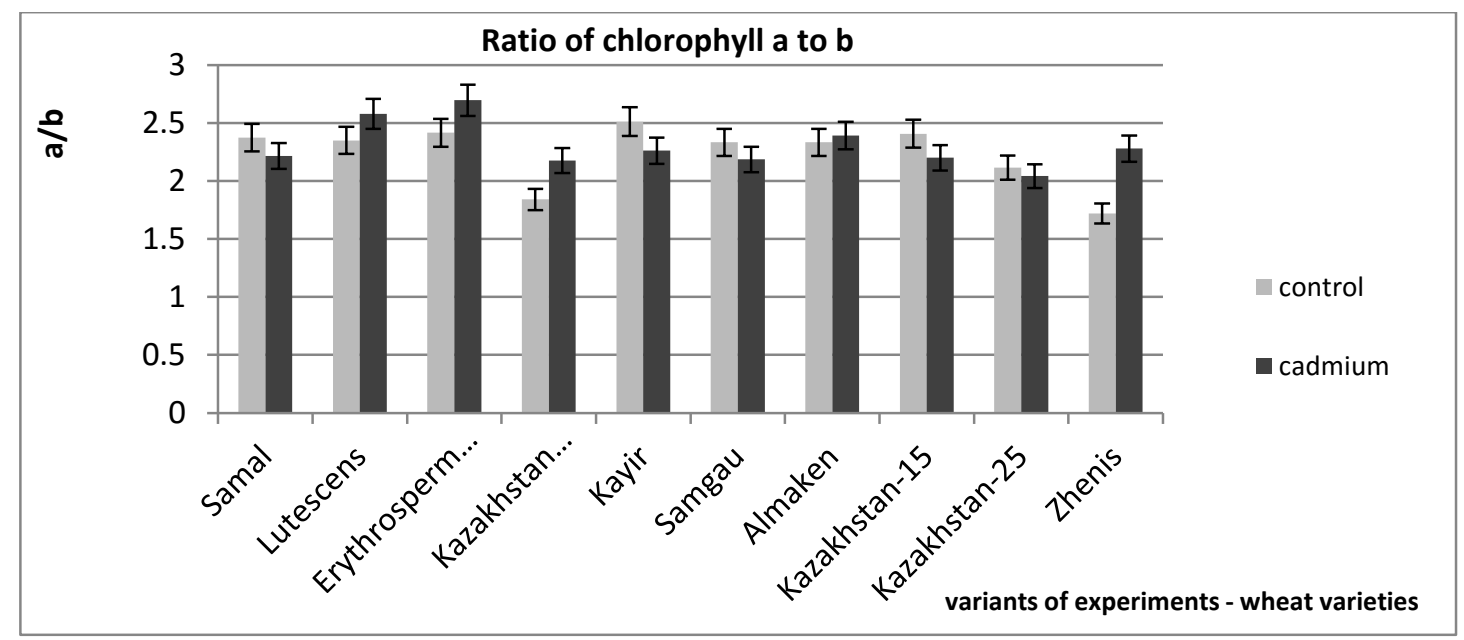

Figure 9. Changing the ratio of chlorophyll $a / b$ in wheat leaves under conditions of contamination with cadmium ions.

The study of the action of cadmium on the content of chlorophyll in wheat varieties, contrasting on resistance to the studied heavy metal, revealed less variability of this indicator in more resistant genotypes to traclocale of cadmium in the aboveground organs compared to the more sensitive. Thus, the study of the impact of pollution with cadmium ions revealed that the number of chlorophyll $a$ and $b$ increases in the leaves of most varieties, which is probably due to the activation of the photosynthetic apparatus caused by high energy costs, which are associated with the neutralization of the influence of pollutants.

\section{Conclusion}

Based on the results, the following conclusions were made:

1. The most resistant to cadmium varieties were Samal and Kaiyr, and the most sensitive - spring wheat variety Lutescens. 
2. The number of chlorophylls $a$ and $b$ increases in the leaves of most varieties, which, apparently, is due to the activation of the photosynthetic apparatus, provoked by high energy costs, which are associated with the neutralization of the influence of pollutants.

3. More resistant varieties showed less variability in the amount of chlorophyll compared with more sensitive.

\section{References}

[1] Wood J. M., 1974, Biological cycles for toxic elements in the environment. Science, V.183, 1049-1059.

[2] Molchan I. M., 1996, Breeding and genetic aspects of reduction of toxicants in crop production. Agricultural biology, № 1, 55-66.

[3] Gamzikova O. I., Barsukov V. S., 1994, The potential of wheat resistance to heavy metals. Siberian ecological journal, № 3, 245-251.

[4] Sokolov O. A., Chernikov V. A., 1999, Economical security and sustainable development. Book 1. Atlas distribution of heavy metals in environmental objects (Puschino, Russian Federation).

[5] Wilkins D. S., 1978. The measurement of tolerance to edaphic factors by means of root growth. New Phytologist, V. 80. №3, 623-633.

[6] Holm, 1954; Wettstein, 1957; Shlyk, 1971, Holm G., Chlorophyll mutations in barley. Acta. Agr. Scand., V. $4,457-471$.

[7] Wettstein D., 1957, Chlorophyll letale und der submikroskopische Formwechsel der Plastiden. Exp. Cell Res., V. 12, 427-434.

[8] Shlyk A. A., 1971, Determination of chlorophylls and carotenoids in extracts of green leaves. Biochemical methods in plant physiology, 154-171.

[9] Titov A. F., Laidinen G. F., Kaznina N. M., 2002, The influence of high concentrations of cadmium on the growth and development of barley and oats in the early stages of ontogenesis. Agrochemistry, № 9, 61-65.

[10] Melnichuk Yu. P., 1990, Effect of cadmium ions on cell division and plant growth. Naukova dumka, 148.

[11] Kaldybaev B. K., 2000, Ecological and genetic assessment of the consequences of pollution of agrocenoses in the eastern part of the Issyk-Kul region farming area. Thesis of abstract of Candidate of Biological Sciences, 28.

[12] Knox R. E., Pozniak C. J., Clarke F. R., Clarke J. M., Houshmand S., Singh A. K., 2009, Chromosomal location of the cadmium uptake gene ( $C d u 1)$ in durum wheat. Genome, Vol. 52, N 9, 741 -747.

[13] Barcelo J., Pochenrieder Ch., 1990, Plant water relations as affected by heavy metal stress: a review. $J$. Plant Nutr., V. 13, № 1, 1-37.

[14] Kaznina H. M., Laidinen G. F., Venzhik Yu. V., Titov A. F., 2013, Effect of cadmium on some anatomical morphological parameters of the leaf and pigment content in barley. Works of Karelian research center of Russian Academy of Sciences, № 3, 52-58.

[15] Nesterenko T. V., Tikhomirov A. A., Shikhov V. N., 2007, Induction of chlorophyll fluorescence and evaluation of plant resistance to adverse effects. Journal of General biology, 444-458.

[16] Kumar P., Prasad M. N. V., 2004, Photosynthetic Pigments and Gaseous Exchangein Cadmium Exposed Ceratophyllum demersum L. (a Freshwater Macrophyte) - a Model for Hormesis. J. Plant Biol, 1-8.

[17] Erofeev E. A., Naumova M. M., 2010, Effect of cadmium sulfate in a wide range of concentrations on physiological and biochemical parameters of wheat seedlings. Bulletin of Nizhny Novgorod University named after N. And. Lobachevsky, № 2(2), 508-512.

[18] A. L. Kornilov, G. A. Petukhov, 2012, The influence of accumulation of heavy metals on the content of pigments of photosynthesis of plants from the coastal zone of reservoirs of the city of Tyumen. Bulletin of Tyumen state University, № 12, 189-194.

[19] Malec P., Maleva M. G., Prasad M. N. V., Strzałka K., 2010, Responses of Lemna Trisulca L. (Duckweed) exposed to low doses of cadmium: thiols, metal binding complexes and photosynthetic pigments as sensitive biomarkers of ecotoxicity. Protoplasma, V. 240, 69-74.

[20] Maleva M. G., Nekrasova G. F., Borisov N., Schukin O. S., Ushakova, 2012, Influence of heavy metals on photosynthetic apparatus and antioxidant status of Elodea. The journal "Plant physiology", № 2, 216-224. 